\title{
Development of Cognitive Learning Model based on Four Noble truths under the Office of the Secondary Educational Service Area
}

\author{
${ }^{1}$ Suthit Sawaddi, ${ }^{2}$ Sin Ngamprakhon, ${ }^{3}$ Suddhipong Srivichai, ${ }^{4}$ Phrakhruwirunsutakhun Uttamasakko \\ 1,2,3,4 Faculty of Education, Mahachulalongkornrajavidyalaya University \\ ${ }^{1}$ suthit.saw@mcu.ac.th, ${ }^{2}$ sin.ngm@mcu.ac.th, ${ }^{3}$ suddhipong.sri@mcu.ac.th, ${ }^{4}$ chaibie2529@ hotmail.com
}

\begin{abstract}
This research article aims to study 1) The cognitive learning condition of students under the Office of the Secondary Educational Service Area 2) Development of cognitive learning model according to the four noble to 3) to propose the cognitive learning model according to the Four Noble Truths. The study model is quantitative and qualitative research. The sample consists of 398 students and focus group discussion participated by 9 experts and document analysis. The results of the research are as follows: 1 . The study results of cognitive learning conditions of students overall is a very good level, all found are the memory, interpretation, apply, discriminant analysis, valuation, and creativity respectively. The results of the students' development of cognitive learning models according to the Four Noble Truths consist of 1) cognitive learning ,there are 6 learning components; 2) learning according to Four Noble Truths, namely (1) determining problems (2) hypotheses (3) analyzing data (4) experimenting and collecting data. 3) The creative learning paradigm consists of 4 areas: (1) learning from experiences (2) learning life skills (3) learning information technology skills (4) brotherhood teaching Activities 3 . The cognitive learning model according to the Four Noble Truths consists of: 1) Learning goals 2) Learning theory concepts that integrate with new knowledge 3) Realizing learning 4) Being able to apply knowledge to it which can be used appropriately for the age and current situation and 5) Learning paradigm in the modern world.
\end{abstract}

Keywords

Cognitive Learning, Four Noble Truths, Secondary Education.

Article Received: 10 August 2020, Revised: 25 October 2020, Accepted: 18 November 2020

\section{Introduction}

The problem of teaching and learning of teachers is basic educational achievement. This is the evaluation of the basic education curriculum at the levels of Mathayom 3 and Grade 6 , which were found to be unsatisfactory. This can be seen from the results of the National Basic Education Test (ONET) in the core subjects. Most of them have an average score lower than the 50 percentage, especially in English, Mathematics and Science. Most of the scores are moderate, and low. In 2011, O-NET scores in the upper secondary level in Thai language subjects had an average score of 52.29 in Science subjects, and social studies The average score was 31.62 and 36.84 , respectively, in the English Language subject, and mathematics, The average scores were 27.36 and 24.82 , respectively, reflecting the different quality of Thai education between schools.[1]

Learners 'learning relative to other countries around the world and in ASEAN, the Program for International Student Assessment (PISA), which focuses on assessing students' ability to apply knowledge, Science Reading and maths from learning to apply to solve problems in life or real situations, it was found that PISA 2015 (2015) average score on science literacy, reading literacy. And mathematics literacy among Thai students aged 15 was below the international average (OECD) of all subjects, with Thailand ranked 55th out of 72 countries, lower than Singapore and Vietnam, ranked 1 and 8, Extinguished respectively. [2] (Ministry of Education National Education Plan 2017-2036: 34-35.)

Bloom's conceptual cognition (Bloom) is a 6 level learning process: 1. Knowledge, memory 2. Understanding 3. Application 4. Analysis 5. Synthesis 6. [3] Valuation, it is the process of changing behavior from old to new or new behavior as a result of experience or practice. It is not a result of natural response or intuition or maturity. As the behavior changed, it must be changed quite permanently. It is considered learning. About the new content making learners more knowledge and understanding of the environment, it is a change that occurs in the brain or past experiences to learn. [4]

Buddhist principles are principles based on any cause and effect, both teaching and learning. In life solving problems it requires a process of thinking, or it can be called. "The Buddhist learning process which is a learning process for the prosperity and prosperity of wisdom." Especially the heart of the Buddha's teachings lies in the Four Noble Truths which the Lord Buddha thought to his old disciples group of five Hermits at Isipatanamarugathayavan Forest, (Now called Sarnath) near Varanasi Clearly indicate their needs It was considered a correct practice, the fairness is not considered right. In Buddhism, it is believed that the learning process of the Four Noble Truths.[5]

The Lord Buddha has shown the cause of suffering and learning processes of the cessation of suffering, which is the process of cause and effect relationships in both the cause of suffering process and the cessation of suffering [6] As the monk namely Assi Thera (The last Thera image in the group of Phra Panchawakani) summarized to show Phra Saribut when he was still uptisaparijak, saying that "no matter what happened. The Tathagata speaks of the causes of the dharma and the quench of those dharma. " [7] (Phra Promkhunaporn (Por.or.Payutto), Buddhist Dictionary, Glossary 2011: 518) From studying the problems mentioned above, the researcher is interested in researching the development of cognitive learning models according to the Four Noble 
Truths for educational institutions under the Office of the Secondary Educational Service Area to present the data obtained from this research to educational institutions under the Secondary Education Service Area Office. It is used as a guideline for learning development for students to have learning quality. Keep up with the changing situation of Thai society and the World society. Throughout the selfdevelopment process of students to continue their learning in the 21 st century.

\section{Research Objectives}

1. To study the cognitive status according to the Four Noble Truths of educational institutions under the Secondary Education Area Office

2. To develop a cognitive learning model according to the Four Noble Truths for educational institutions.

3. To propose a learning model for cognitive behavior according to the Four Noble Truths for educational institutions.

\section{Research Methods}

\section{Scope of content}

Subject research The Development of the Cognitive Learning Model according to the Four Noble Truths for Educational Institutions under the Secondary Educational Service Area Office, the researcher has set up the content scope in accordance with the following concepts, theories and related research.

1) Contents about Phutthiphisai 6 (Cognitive Domain) [8] including knowledge and understanding, use of side Analysis Synthetic and valuation aspects and the Four Noble Truths, namely suffering, Somuthai (cause of suffering), Nirot (cessation of sufferring) and Mak. (Noble path to cessation of sufferring) [9]

2) Content about learning, including meaning learning, learning process, characteristics of the 21 st century learner.

3) Content on the learning model (Model) includes the importance and meaning of the model (Model) learning, types of learning models. The good nature of the learning style, popular evaluation model, learning model development process, and examining the learning style, creative learning paradigms and related research.

2. Population and sample scope

Population and sample groups used for research are as follows.

1) The population is middle and high school students. Schools under the Secondary Educational Service Area Office, Surin with, 25,509 people

2) The sample group is 398 junior high school students and senior high school students.

3.Key informants

1) Provider of important information in the study on the development of the four Noble Truths learning models for educational institutes, totaling 4 images / person, was selected in specific interviews with expertise in Buddhism.

2) Group Chat (Focus Group Discussion) to bring information obtained from group discussion (Focus Group Discussion).

4. Methods of conducting research
1) Research model The Development of the Cognitive Learning Model according to the Four Noble Truths for Educational Institutions under the Secondary Educational Service Area Office, this research is a mixed research method, mainly using quantitative research, and supporting qualitative research, and the researcher has carried out with the following steps.

Step 1: To study the condition of the cognitive learning model development according to the Four Noble Truths for educational institutions.

1. To study information on the development of the cognitive learning model according to the Four Noble Truths as follows:

1.1 Research sources are books, journals, textbooks, related research articles.

1.2 The research tool is a study of document for the development of a cognitive learning model according to the Four Noble Truths.

1.3 To interview with experts about the development of cognitive learning model

1.4 Statistical analysis of content for percentage and Lisrel Program

2. Study data from questionnaires regarding the development of the cognitive model based on the Four Noble Truths for educational institutions as follows:

2.1 The research source is a sample of 398 high school students.

2.2 The research tool is a questionnaire concerning the development of the cognitive learning model according to the Four Noble Truths for educational institutions, under the Office of the Secondary Educational Service Area.

2.3 Statistical analysis of content for percentage and Lisrel Program

3. Study the condition of the cognitive learning model development according to the Four Noble Truths as follows: 3.1 The research source is the experts who have given interview data, 4 photos / person.

3.2 The research tool is an interview form on the development of the cognitive learning model according to the Four Noble Truths for educational institutions, under the Office of the Secondary Educational Service Area.

3.3 Statistical analysis of content for percentage and Lisrel Program

Step 2 Development of cognitive learning models according to the Four Noble Truths for educational institutions under the Office of the Secondary Educational Service Area are as follows :

1. Drafting questionnaires about the development of the cognitive learning model according to the Four Noble Truths for educational institutions as follows:

1.1 The research source is the results obtained from Objective 1.

1.2 The research tool is a questionnaire.

1.3 Statistical analysis of content for percentage and Lisrel Program

2. Discussion held with a focus group on the development of cognitive learning models.

2.1 The research source is 4 photos / person interviewing experts.

2.2 Research tool for interview. 
Step 3 presents the development of cognitive learning models according to the Four Noble Truths for educational institutions.

1. To check the development of the pattern: to verify the validity of the cognitive learning model according to the Four Noble Truths for educational institutions as follows:

1.1 The research source is a sample of 398 high school students.

1.2 The research tool is a questionnaire.

1.3 Statistical analysis of content for percentage and Lisrel Program

2. Improvement and present action the format is

2.1 The research source is the main advisor. Co-advisor and researcher

2.2 The research tool is a questionnaire on the development of the cognitive learning model according to the Four Noble Truths.

2.3 Statistical analysis of content for percentage and Lisrel Program

4.2 Research tools

The research tools are as follows.

1.. Checklist form based on opinions of junior and senior high school students on the development of the 6 cognitive learning models according to the Four Noble Truths.

2. Interviewing is an interview form for the development of cognitive learning patterns according to the Four Noble Truths principles as follows:

1. To study the concept of the development of a cognitive learning model 6, namely, knowledge, understanding (Comprehension) in use (Application) Analysis, Synthesis, Evaluation.

2. To study the concept of developing a learning model in Phutthi Phisai according to the Four Noble Truths: Suffering, Happiness, Nirod, and Mak.

3. To inspect the quality of research instruments on The development of cognitive learning models according to the Four Noble Truths for educational institutions are as follows:

3.1 The draft questionnaire is presented to the Chairman and the two advisors for further review for further improvement.

4.3 Collection of information

Collection of research data on the development of cognitive learning models according to the Four Noble Truths for educational institutions as follows:

1. The researcher contacts and coordinates with the Ph.D. Program of Buddhist Education requesting for a letter to seek a coperation from a targe school to collect the filled up questionnaires from a sample of 398 people.

2. Researcher conducts field operations, to contact for collecting interview forms experts taking notes and audio recordings, signig the photos in the most realistic storage. They were then returned to check the correctness of the questionnaire for further analysis.

4.4 Data analysis

Analysis of research data, the development of cognitive learning models according to the Four Noble Truths are as follows:

1. The researcher takes the collected gathered from the distribution of questionnaires such as interviews and group discussions, and use questionnaires to analyze in order to create new knowledge.
1.1 Quantitative data analysis : It is a statistical analysis of the content for percentage and Lisrel Program.

1.2 Qualitative data analysis The statistical analysis has been performed for percentage values and the Lisrel Program has been based on the results from expert interviews, group discussion. To analyze the content and check the correctness of the information according to the concept [10] .

\section{Research findings.}

The results of analysis of student opinion questionnaire on the development of the cognitive learning model according to the Four Noble Truths for educational institutions, under the Office of the Secondary Educational Service Area by using statistical analysis of mean $(\overline{\mathbf{X}})$ and standard deviation (S.D.) on cognitive learning conditions according to the Four Noble Truths under the Secondary Education Area Office from a sample of junior high school and senior high school students, under the Secondary Educational Service Area Office with 398 people, the results are as follows:

\begin{tabular}{|c|c|c|c|c|}
\hline \multirow{3}{*}{$\begin{array}{l}\text { The learning } \\
\text { conditions of the } \\
\text { cognitive aspects } \\
\text { of all } \\
6 \text { aspects }\end{array}$} & \multicolumn{4}{|c|}{$\mathrm{n}=398$ persons } \\
\hline & \multicolumn{4}{|c|}{ Student reviews } \\
\hline & $\overline{\mathrm{x}}$ & S.D. & Level & \\
\hline 1. Knowledge & 3.76 & 0.54 & high & 1 \\
\hline $\begin{array}{l}\text { 2. Comprehen } \\
\text { sion }\end{array}$ & 3.49 & 0.62 & high & 5 \\
\hline Application & 3.61 & 0.68 & high & 4 \\
\hline Analysis & 3.01 & 0.72 & medium & 6 \\
\hline Synthesis & 3.63 & 0.67 & high & 3 \\
\hline Evaluation & 3.70 & 0.63 & high & 2 \\
\hline Total & 3.52 & 0.55 & high & \\
\hline
\end{tabular}

To propose a learning model on cognitive traits according to the Four Noble Truths for educational institutions under the Secondary Educational Service Area Office.

To propose a learning model on cognitive traits according to the Four Noble Truths for educational institutions under the Secondary Educational Service Area Office. And to be consistent with the results of the examination of the cognitive development model according to the Four Noble Truths by experts from the Focus Group Discussion meeting on examination of the learning model development of secondary school students in Phutthi Phisai (Cognitive Domain) according to the Four Noble Truths for educational institutions under the Secondary Education Service Area Office from groups discussion (Focus Group Discussion) can be summarized as follows.

1. To improve the learning style to have a clear sequence of elements.

2. To add up explanations, expand the vocabulary to be clear and complete.

3. To adjust the cognitive elements to be in line with the Four Noble Truths.

4. To examine the wrong words and complete correctness of the development of the learning pattern of secondary school students in the field of cognition according to the Four Noble Truths for educational institutions, under the Office of the Secondary Educational Service Area 
5. The learning of students in the field of knowledge according to the principles of the theory 4 for educational institutions under the Secondary Education Area Office should go through the learning process by organizing cognitive learning activities according to the principles of Ariyasaj (Four Noble Truths)

5.1 Vocabulary learning activities are : teachers and students explain steps and play methods such as use of pictures, vocabulary, card and slide card machines.

5.2 Learning activities on life problems are : activities that enhance and develop life skills, which must be a studentcentered activity. Life of students and be aware of the changes in society, choosing solutions for the appropriate reasons to have constructive results, making life go on with happiness.

5.3 activities to know the use of IT system is the learning of the students, to be a student who learns in the world and is updated up with the latest news. Digital technology transformation, Knowing how to develop oneself and being able to adapt to the changes that will occur in creating learning advantages in activities related to daily life.

5.4 Activities for friends, partners, and friends are learning activities for learners to learn together and help each other during joint learning activities. It is a creative activity aiming at students to have good study habits and good habits. "Friendship by Friendship" is an activity to train the use of ideas in the creation of work, promoting imagination and creativity according to the potential of the individual

\section{Discussions}

Research results on the development of the learning model of secondary students in the field of cognition according to the Four Noble Truths for educational institutions under the Office of the Secondary Educational Service Area from the study of concepts, theories, principles, processes, analysis and synthesis of knowledge according to the cognitive learning elements according to the Four Noble Truths, it can be summarized as a body of knowledge for learning as an innovative knowledge set. The Four Noble Truth for educational institutions under the Secondary Educational Service Area Office gained knowledge as in Figure1

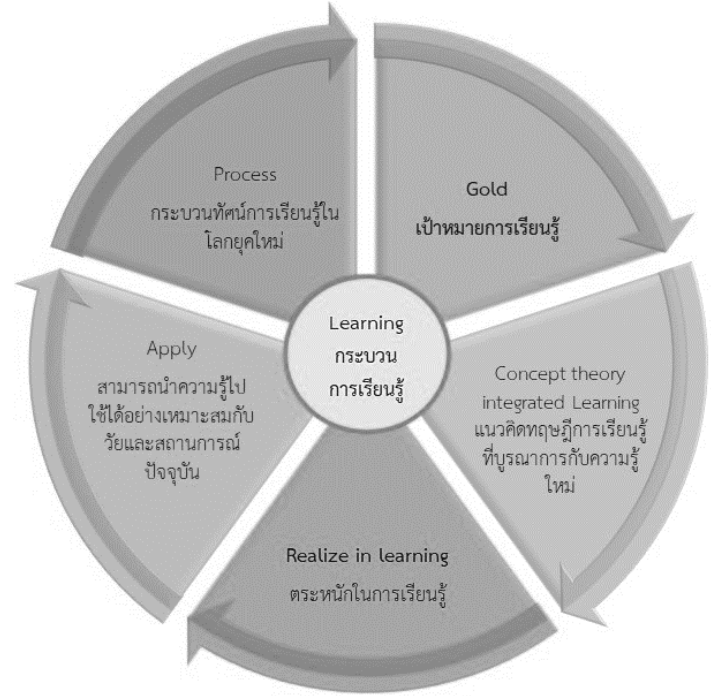

Figure 1 Knowledge gained from research L: CGRAP MODEL Source: Suthit Sawadee 2020
From Figure 1, the knowledge of the development of the learning model of secondary school students in the field of cognition according to the Four Noble Truths for Educational Institutions under the Secondary Educational Service Area Office, it is a New Process learning MODEL as follows.

G: Gold The learning goal is that the student's potentiality can be stimulated by the creative reflection of the teacher. It is the role that helps students Envision the learning process towards achieving the goals of 21 st century learning, leadership is able to adapt appropriately to cause and effect as well as self-responsibility. To build good relationship with people including communication, and imagine the way of success

C: Concept theory integrated learning The concept of learning theory integrated with new knowledge is that students can use the concept theory integrated learning, integrated with new knowledge or leadership as a tool for developing themselves as good people, good, virtuous, and capable of developing new knowledge

$\mathrm{R}$ : Realize in learning : The awareness of learning is that students can create a brand and image. The work is visible and reliable, to create a learning network to receive new information Learning is as valuable as starting a life going forward in the future.

A: Apply knowledge to be appropriate for age and situation. Students can apply knowledge appropriate to their age and current situation, i.e. students know their role in learning, and has a thorough resolution, does not ignore the little things, observant, has a good sense of time, has intelligence, hasa good leadership spirit, and has a positive mindset

$\mathrm{T}$ : The learning paradigm in the modern world : The learning paradigm in the modern world is that students know the analytical thinking process. New ways of operating are in line with the times and situations that are happening and that will happen in the future.

\section{Recommendations}

Suggestions for applying research results

1. The results of the research have indicated that the overall cognitive learning, cognitive knowledge Use side Analysis Synthetic Evaluation is at a high level, so those involved parties should be aware of the potential development of learners in knowledge, understanding, and applying synthetic analysis to be more effective.

2. The results of the research have indicated that the overview of learning of the four noble truths to create a creative learning paradigm used to develop learning competencies for learners to increase the potential for learners to develop themselves.

\section{References}

[1] Ministry of Education. National Education Plan 2017-2036. Office of the Education Council Secretariat Bangkok: Printed at Prik Wan Graphic Company, 2017.. 
[2] Kingkaew Arirak, Knowledge Management using multiple formats, Bangkok: Methee Tip, 2005..

[3] Pimphandechkrupt. Skills of Hole $7 \mathrm{C}$ of Teachers 4.0. 2nd edition. Bangkok: Chulalongkorn University Press, 2017.

[4] Phra Promkhunaporn (Por.Payutto). Buddhist dictionary Code of Dhamma. Bangkok:

Mahachulalongkornrajavidyalaya University Press, 2003.

[5] Sutat Pongkulbut, Cultivating virtue Ethics for students, Arts and Culture Center: Sripatum University, 2007.

[6] Bloom, Benjamin S. and Others. 1956. Taxonomy of Educational Objectives. New york : David McKay Co., Inc.

[7] Supang Chantawanich. A qualitative research method. Bangkok: Chulalongkorn University Press, 2544.

[8] Thanin Silpjaru. Research and analysis of statistical data by SPSS. 9th edition. Bangkok: Printed at S.R. Printing Mass Products Co., Ltd., 2008. 